\title{
Dissociations of Face and Object Recognition in Developmental Prosopagnosia
}

\section{Citation}

Duchaine, Brad, and Ken Nakayama. 2005. Dissociations of face and object recognition in developmental prosopagnosia. Journal of Cognitive Neuroscience 17(2): 249-261.

\section{Published Version}

doi:10.1162/0898929053124857

\section{Permanent link}

http://nrs.harvard.edu/urn-3:HUL.InstRepos:11064634

\section{Terms of Use}

This article was downloaded from Harvard University's DASH repository, and is made available under the terms and conditions applicable to Other Posted Material, as set forth at http:// nrs.harvard.edu/urn-3:HUL.InstRepos:dash.current.terms-of-use\#LAA

\section{Share Your Story}

The Harvard community has made this article openly available.

Please share how this access benefits you. Submit a story.

Accessibility 


\title{
Dissociations of Face and Object Recognition in Developmental Prosopagnosia
}

\author{
Brad Duchaine and Ken Nakayama
}

\begin{abstract}
Neuropsychological studies with patients suffering from prosopagnosia have provided the main evidence for the hypothesis that the recognition of faces and objects rely on distinct mechanisms. Yet doubts remain, and it has been argued that no case demonstrating an unequivocal dissociation between face and object recognition exists due in part to the lack of appropriate response time measurements (Gauthier et al., 1999). We tested seven developmental prosopagnosics to measure their accuracy and reaction times with multiple tests of face recognition and compared this with a larger battery of object recognition tests. For our systematic comparison, we used an old/new recognition memory paradigm involving memory tests for cars, tools, guns, horses, natural scenes, and houses in addition to two separate tests for faces.
\end{abstract}

\section{INTRODUCTION}

Over the last 20 years, a number of neuropsychological cases have shown dissociations between impaired face recognition and normal or relatively spared nonface recognition (Henke, Schwinbuerger, Grigo, Klos, \& Sommer, 1998; Farah, Levinson, \& Klein, 1995; Farah, Wilson, Drain, \& Tanaka, 1995; McNeil \& Warrington, 1993; De Renzi, 1986). These cases have provided crucial support for the hypothesis that face recognition relies on different mechanisms than nonface recognition. However, the failure to measure response time in these cases leaves open the possibility that speed-accuracy tradeoffs can account for these accuracy dissociations (Gauthier, Behrmann, \& Tarr, 1999), and it has been argued that no unequivocal cases have been documented that show impaired face recognition with normal nonface recognition. Herein, we discuss the results of testing that we have done with a relatively large sample of developmental prosopagnosics (DPs) that aims to determine whether face recognition and nonface recognition can dissociate.

Harvard University
Developmental prosopagnosic subjects performed very poorly with the face memory tests as expected. Four of the seven prosopagnosics showed a very strong dissociation between the face and object tests. Systematic comparison of reaction time measurements for all tests indicates that the dissociations cannot be accounted for by differences in reaction times. Contrary to an account based on speed accuracy tradeoffs, prosopagnosics were systematically faster in nonface tests than in face tests. Thus, our findings demonstrate that face and nonface recognition can dissociate over a wide range of testing conditions. This is further support for the hypothesis that face and nonface recognition relies on separate mechanisms and that developmental prosopagnosia constitutes a disorder separate from developmental agnosia.

\section{Developmental Prosopagnosia}

Until the last few years, nearly all of the prosopagnosics documented in research articles acquired their face recognition impairments as adults due to trauma, stroke, or degenerative disease. In the comprehensive review of agnosia by Farah (1990), she listed approximately 80 cases of acquired prosopagnosia. At the time, there were only two reports of individuals who did not acquire prosopagnosia as adults (Tranel \& Damasio, 1989; McConachie, 1976). Recently, however, a number of articles have documented such individuals (Duchaine, Dingle, Butterworth, \& Nakayama, 2004; Barton, Cherkasova, Press, Intrilligator, \& O'Connor, 2003; Duchaine, Nieminen-von Wendt, New, \& Kulomaki, 2003; Duchaine, Parker, \& Nakayama, 2003; Hasson, Avidan, Deouell, Bentin, \& Malach, 2003; Michelon \& Biederman, 2003; Pietz, Ebeinger, \& Rating, 2003; Jones \& Tranel, 2001; Laeng \& Caviness, 2001; Nunn, Postma, \& Pearson, 2001; de Gelder \& Rouw, 2000; Duchaine, 2000; Farah, Rabinowitz, Quinn, \& Liu, 2000; Bentin, Deouell, \& Soroker, 1999; de Haan, 1999). Rather than losing mature face recognition abilities, these individuals failed to develop the face recognition skills seen in most adults. These individuals have been most commonly referred to as DPs, and they hold great promise for understanding the computational, developmental, and genetic mechanisms involved with face recognition. 
We made contact with the majority of these individuals after they responded to our web site that discusses our research on prosopagnosia (www.faceblind.org). In the 2 years since we set up our web site, we have been contacted by more than 175 self-reported prosopagnosics. Few of these individuals were aware of any incidents that could have caused their impairment, so it appears that, contrary to the proportions in the literature, most cases of prosopagnosia are not the result of brain damage sustained during adult years but rather result from an anomalous developmental course.

DP has been used to refer to individuals whose prosopagnosia is due to a genetic condition (Duchaine, Nieminen-von Wendt, et al., 2003; Bentin et al., 1999; de Haan, 1999), brain damage (both prenatal and during childhood) (Barton et al., 2003; Michelon \& Biederman, 2003; Farah et al., 2000), and unknown causes. Living with DP can be very difficult. Some DPs are able to manage fairly well in social situations, but many prefer to limit their social activities to avoid placing themselves in situations in which person recognition is necessary. The following quote comes from an email written to one of the authors by a DP:

\section{I think prosopagnosia has worsened my current depression, if not been a root cause of it. This condition always affects my ability to form normal social links to others. I prefer to be a recluse because I can't confidently function any other way. My avoidance of people (to interact with socially) is nearly phobic.}

Many compensate by relying on information other than facial structure, and the most commonly reported alternative routes to identification include hair, clothing, voice, and gait (Barton et al., 2003; Duchaine, Nieminenvon Wendt, et al., 2003; Nunn et al., 2001; Duchaine, 2000). When these means fail, DPs often use conversational topics to determine identity. Because face recognition usually occurs almost instantaneously, these less reliable and slower methods often are not sufficient to successfully manage social situations. Some individuals with face recognition impairments have been diagnosed with autism or Asperger syndrome (Duchaine, Nieminenvon Wendt, et al., 2003; Blair, Frith, Smith, Abell, \& Cipolotti, 2002; Cipolotti, Robinson, Blair, \& Frith, 1999; Davies, Bishop, Manstead, \& Tantam, 1994), whereas others appear to be socially typical aside from their problems with face perception. In addition, a sizeable proportion of DPs who have contacted us report severe navigational impairments (Duchaine, Parker, et al., 2003) and number have been diagnosed with central auditory processing deficit, which is characterized by difficulty understanding speech in noisy settings (Duchaine, 2000).

Interestingly, many DPs do not identify their disorder until well into adulthood (Duchaine, Parker, et al., 2003; Laeng \& Caviness, 2001; Duchaine, 2000). There are probably a few factors that contribute to this surprising lack of awareness. First, unlike prosopagnosia acquired in adulthood, DPs are not able to compare their impaired abilities to previously normal abilities. In addition, DPs often develop refined abilities to use other methods of identification. Finally, a number of DPs have mentioned asking relatives about person recognition, only to be told that everyone has trouble with it. However, family members are likely to be an unreliable source in this regard, because approximately $20 \%$ of the respondents to our web site report relatives with face recognition problems and we have confirmed it in three families (Duchaine, Nieminen-von Wendt, et al., 2003; see also de Haan, 1999). That intelligent people can be unaware of an impairment to an ability as critical as face recognition hints that many people may have perceptual or cognitive blind spots that are never identified.

\section{The Development of Face Perception}

We mentioned above a number of precipitating causes that can lead to developmental prosopagnosia, but we have little understanding how these factors affect the development of face processing abilities. Gaining such an understanding is challenging, because the development of face perception involves a number of mechanisms and the acquisition of mature face perception skills is not complete until late adolescence (Mondloch, Le Grand, \& Maurer, 2002; Carey, Diamond, \& Woods, 1980). Infants are born equipped with mechanisms, possibly subcortical, that direct attention to faces (Johnson, Dziurawiec, Ellis, \& Morton, 1991; Goren, Sarty, \& Wu, 1975), and experiments have shown that they engage in sophisticated face processing early in life. Newborns can recognize their mother's face via the external features (Pascalis, de Schonen, Morton, deRurelle, \& FabreGrenet, 1995; Bushnell, Sai, \& Mullin, 1982), and by 8 weeks, they begin to use the internal features as well (Blass \& Camp, 2004). In addition to facial identity, work has shown that infants make fine discriminations for facial attractiveness (Slater, Bremner, Slater, \& Mason, 2000; Slater et al. 1998), facial expressions (Field et al., 1982; see also work in macaques, Sackett, 1966), and eye gaze direction (Blass \& Camp, 2001).

Object recognition typically involves feature processing (Biederman, 1987), but face recognition also involves holistic processing and configural processing (McKone, Martini, \& Nakayama, 2001; Freire, Lee, \& Symons, 2000; Tanaka \& Farah, 1993; Young, Hellawell, \& Hay, 1987). Holistic processing is characterized by the integration of facial information into a gestalt (Tanaka \& Farah, 1993; Young et al., 1987), whereas configural processing usually describes sensitivity to the precise spatial layout of the facial features (Freire et al., 2000; Diamond \& Carey, 1986) or features in the context of a facial image (McKone et al., 2001; Tanaka \& Farah, 1993). Some evidence indicates that the mechanisms which carry out these computations are dissociable neuropsychologically 
(Le Grand et al., 2001; Barton et al., 2002), developmentally (Carey \& Diamond, 1994; Mondloch et al., 2002), and behaviorally (Freire \& Lee, 2000; Le Grand et al., 2001), though recent behavioral and neuroimaging work has questioned this conclusion (Yovel \& Kanwisher, in press). Feature processing and holistic processing appear to operate at an early age (Carey \& Diamond, 1994; Tanaka et al., 1998), but the age at which configural processing emerges is unclear. Some studies indicate that configural processing does not reach adult levels until adolescence (Carey and Diamond, 1994; Mondloch et al., 2002), but this has been challenged by findings showing that the inversion effect does not increase after age eight (Itier \& Taylor, 2004). Interestingly, although face recognition continues to improve throughout childhood (Carey \& Diamond, 1994; Mondloch et al., 2002), it does not reach adult-levels without visual input to the right hemisphere during the first six months of life (Le Grand et al., 2001; 2003).

This brief review makes it clear that there are many possible ways that such a complex and protracted process could be disrupted. An absence of normal input to right hemisphere mechanisms could arise for any number of reasons: lack of social contact, failure to direct attention to faces, or low-level visual problems such as infantile cataracts, severe uncorrected myopia, or amblyopia in which input from the left eye is suppressed. The many cortical recognition mechanisms involved with face recognition could fail to develop due to environmental factors, genetic deficits, or brain damage anytime during development. Except in cases of brain damage (Michelon \& Biederman, 2003; Laeng \& Caviness, 2001; Farah et al., 2000) or visual deprivation (Le Grand et al., 2001, 2003), it is difficult to determine the factors contributing to abnormal development after difficulty with faces has become apparent. One promising approach lies in longitudinal studies of children who are more likely to develop prosopagnosia such as those with limited early visual input, posterior brain damage, or a family history of prosopagnosia.

\section{Abilities Other Than Face Recognition in Developmental Prosopagnosia}

A small number of case studies have investigated visual recognition abilities other than face identification in DP, and these reports have shown that some DPs are impaired with other abilities, whereas some are normal (see Galaburda \& Duchaine, 2003, for a review). This mixed outcome is true for recognition of facial expressions of emotion, age discrimination, and sex discrimination. Similarly, nonface object and place recognition has been shown to be impaired in some DPs, whereas others appear to show normal recognition of at least some nonface classes (Duchaine, Nieminen-von Wendt, et al., 2003; Nunn et al., 2001; Bentin et al., 1999). The heterogeneity that has been found for these different abilities is similar to that found with individuals with acquired prosopagnosia (Galaburda \& Duchaine, 2003).

Our web site has allowed us to study a relatively large number of DPs, and we are investigating a range of abilities to better understand this array of conditions. Our testing is addressing DP's low- and midlevel perceptual abilities, recognition of identity, expressions of emotion, attractiveness, and sex via the face, and the neural basis of their processing impairments. Herein, we will focus on their recognition of items from nonface classes.

\section{Nonface Discrimination and Issues in Prosopagnosia}

Tests of nonface recognition in DPs enable us to address a number of important questions regarding the mechanisms of visual recognition. First, are the recognition impairments of DPs restricted to tasks involving faces or do they also include other classes? A number of case studies have addressed this question in acquired prosopagnosia (Gauthier et al., 1999; Henke et al., 1998; Farah, Levinson, et al., 1995, Farah, Wilson, et al., 1995; McNeil \& Warrington, 1993), but the nonface recognition abilities have only been formally tested in a few DPs (Duchaine, Nieminen-von Wendt, et al., 2003; Jones \& Tranel, 2001; Nunn et al., 2001). If our testing shows that these DPs are impaired with faces and comparable nonface categories, this is consistent with the existence of a single recognition mechanism that is used for face and nonface discriminations (Tarr \& Cheng, 2003). However, if face recognition and nonface recognition rely on different mechanisms (at least in normal subjects), there may be DP individuals who show dissociations between face and nonface discrimination. Note that the existence of separate mechanisms does not predict that all DPs will show dissociations between face and nonface recognition but only that some will. Neuroimaging studies indicate that face and nonface recognition involve overlapping brain areas (Grill-Spector, 2003; Haxby et al., 2001; Kanwisher, 2000), so it seems quite likely that these abilities, if they are separable, will rely on many common developmental processes, which, when anomalous, will often affect both types of recognition. In addition, there may be computational mechanisms that are used for recognizing both faces and nonfaces.

If the single mechanism account is correct, prosopagnosia and agnosia are not distinct conditions. Although there has been general agreement that prosopagnosia is a discrete condition since Bodamer (1947) first characterized it, a review by Gauthier et al. (1999) questioned this classification. The review found that although there were accuracy results showing impaired face recognition coupled with normal or relatively spared nonface recognition (Nunn et al., 2001; Bentin et al., 1999; Henke et al., 1998; Farah, Levinson, et al., 1995; Farah, Wilson, et al., 1995; McNeil \& Warrington, 1993), response time was almost never measured so speed/accuracy tradeoffs may 
have given rise to the dissociation. In particular, they suggested that subjects may have responded very slowly to test items in the putatively normal nonface tests and this allowed these subjects to pull their scores into the normal range. Given such long time intervals, such individuals could have used special strategies to perform the task that have little to do with normal object recognition. Thus, they argue that there has never been a case of showing an unequivocal dissociation between face and nonface recognition, and so Gauthier et al. cast doubt on the idea that prosopagnosia actually exists as a separate entity from agnosia.

Our results will better address the issues discussed above than past reports for three reasons. First, no DP samples of this size have been tested before. Second, we will measure response time to determine if speed/accuracy tradeoffs may account for any dissociations that we may find. Lastly, we will test nonface discrimination with far more classes than is typically used. In past reports, one or two nonface classes were typically used whereas we will use six nonface classes.

The results of our testing will also provide insight into the developmental processes that construct mechanisms of object recognition. Dissociations in acquired prosopagnosia reveal little about development, because damage occurs after recognition abilities have fully matured. In contrast, DPs were unable to develop normal face recognition abilities so normal abilities with other visual classes would suggest that the underlying mechanisms are built, at least in part, by different developmental processes. In addition, poor face recognition with normal object recognition would demonstrate that functioning object mechanisms cannot compensate for the impaired mechanisms normally used with faces (Farah, Wilson, et al., 1995). Finally, past studies of abilities other than facial identity have indicated that DP is not a homogeneous condition (Galaburda \& Duchaine, 2003). Testing our relatively large sample of DPs with identical tests allows us to directly address this issue.

\section{RESULTS}

All of the following tests used the old/new recognition memory paradigm described in the Methods section. During the study phase of the experiment, subjects were instructed to memorize the target images, and then they attempted to discriminate between the target images and the nontarget images in the test phase. Seven prosopagnosics were included in our DP sample. As discussed in the Methods section, these individuals reported severe face recognition problems in everyday life. Each scored more than 2 standard deviations below the control mean on at least three of four tests of face recognition. We labeled the DPs by sex (F or M) and number. The 17 control participants were graduate students without extensive experience in perceptual experiments. Each control participant produced a score for each old/

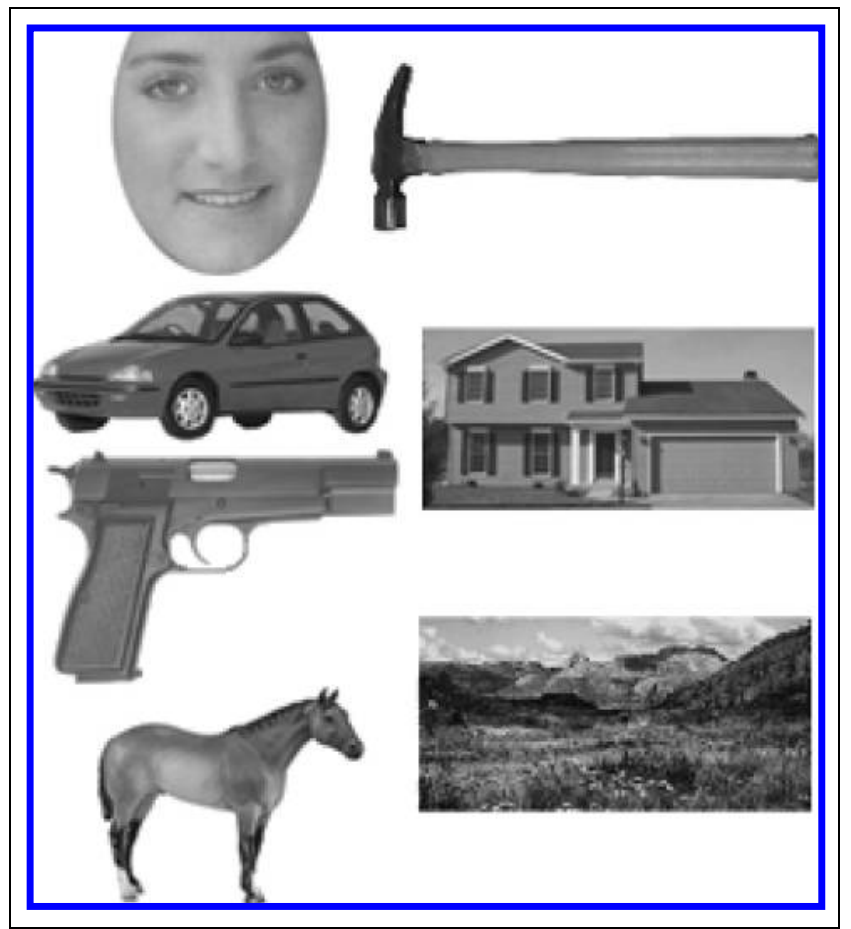

Figure 1. Items from the old/new discrimination tests.

new test except for four instances out of a possible 136 (17 controls $\times 8$ tests). Examples of the stimuli from the different categories used in the experiments below can be seen in Figure 1.

We used $A^{\prime}$ as the measure of discrimination in the following comparisons. It is a bias-free measure that varies between 0.5 and 1.0 with higher scores indicating better discrimination (Macmillan \& Creelman, 1991). Unlike $d^{\prime}, A^{\prime}$ values can be computed when cells with zero responses are present. To estimate the standard error for each subject for each test, we performed a bootstrap analysis, resampling 1000 times from the data set of each DP and each control subject. This provides us with an estimate of the standard deviation in their $A^{\prime}$ scores (Efron \& Tibshirani, 1993). The simulations used random sampling with replacement from within sets of target and nontarget test trials.

\section{Face Discrimination}

Because performance with objects will be assessed with old/new tests, it is necessary to confirm that our DPs are severely impaired with faces in this paradigm. We used two face discriminations to assess their performance, and the tests were identical except that each used a different set of 40 faces. The symbols in Figure 2 show the individual $A^{\prime}$ scores for each DP and each control subject for the two face tests. In this and subsequent graphs, each DP is identified by a distinct colored symbol (men in blue, women in pink). The nonoverlap- 


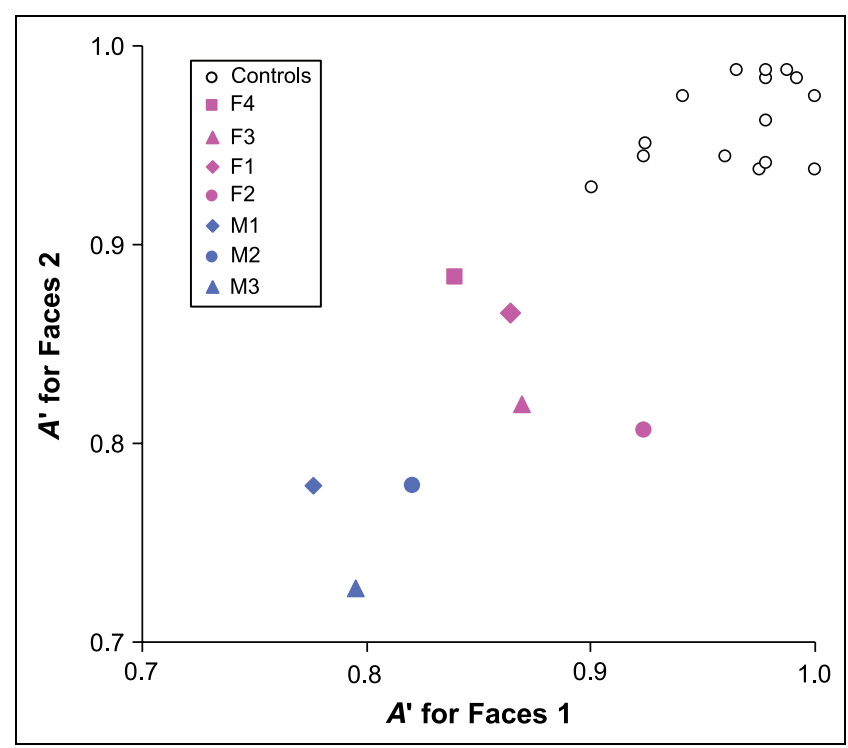

Figure 2. $A^{\prime}$ scores for DPs (colored shapes) and control subjects (open circles) on the two face old-new discriminations (Faces 1 and Faces 2). Each DP is identified with individual symbols ( pink symbols $=$ women, blue symbols $=$ men) and numbers. These symbols remain the same in Figures $2-5$.

ping cluster of the individual DP scores confirms that they are severely impaired with faces.

\section{Nonface Discriminations}

Figure 3 shows the distribution of $A^{\prime}$ scores for each DP and control subject for the nonface discriminations. To better display the relative performance of each DP subject with respect to the control population, scores are ordered according to performance. Each DP is uniquely identified as described above. It is clear that for a few of the nonface discriminations the DP subjects were amongst the poorest performers. This is most evident for cars and guns where the worst performing subjects were the DPs and the better performing DPs were mostly confined to the bottom half of the normal sample. From this pattern of results, it suggests that some DP subjects in our sample are likely to be agnosic with a broad pattern of recognition disabilities.

However, for many of the nonface tests, $A^{\prime}$ scores for the DPs are scattered over the normal range. Two DPs scored within the normal range on all of the nonface tests (see scores of M1 and M2), one scored in the low end of the normal range in all of the tests (F2) and one scored within the normal range for all but one test (M3). A majority of the DPs scored in the normal range on the tools, horses, scenes, and houses tests. There were a total of 38 nonface $A^{\prime}$ scores for the DPs, and 22 of these scores were within 1.5 standard deviations of the control mean.

As such, it looks like for this group of 7 subjects, there is considerable heterogeneity, some subjects seem to show what looks like normal object recognition while having severe deficits in face processing. This is particu- larly evident for the three male DP subjects who happened to perform especially badly at the faces task (see blue symbols in Figure 2). If a single recognition mechanism is used to recognize all classes of stimuli, then these subjects, performing so poorly on the face tasks, should be the poorest performers in the object tasks as well. This is clearly not the case, indicating that there is indeed a dissociation between face and object processing in a significant number of our prosopagnosic subjects.

To address this point more systematically, we constructed a simple linear model, making the assumption that face and nonface perception require the same abilities. If this were the case, performance on face discrimination tasks should provide an unbiased estimate for performance on the nonface discriminations. If true, it would strongly support Gauthier et al.'s (1999) implication that prosopagnosia does not constitute a disorder separate from agnosia. On the other hand, if nonface recognition performance was superior to that predicted, we would have to conclude that at least in some individuals, there is a dissociation between face and nonface processing. We constructed the simple linear model as follows. First, we estimated the relative difficulty of each test $\left(T_{j}\right)$ by computing the average performance of the control subjects. Next, we used the performance of all subjects on Faces 1 and Faces 2 to estimate their recognition ability $\left(A_{i}\right)$. Using these two variables, test difficulty $\left(T_{j}\right)$ and general recognition ability $\left(A_{i}\right)$, we predicted performance on all other tests as expressed in Equation 1:

$$
P_{i j}=T_{i}+A_{j}
$$

where the performance $\left(P_{i j}\right)$ of the $i$ th subject on the $j$ th test is simply the sum of these factors.

Expressing these as $A^{\prime}$ scores leads to a separate plot for each test with each point representing predicted versus observed performance of each subject (see Figure 4). Not surprisingly, these predictions are born out by the scores of the faces tests shown on the top two panels where they hug the $45^{\circ}$ diagonal line prediction. Of greater interest is the pattern of results for the nonface tests. First let us consider the normal controls on all of the tests (open circles). They do not deviate systematically from the $45^{\circ}$ identity line. As such, the face tests provide an unbiased estimate of the performance on the nonface tests of the control subjects.

Of greatest interest is the pattern of data obtained from the prosopagnosic subjects (colored symbols). The three male subjects (in blue) all fall well above the diagonal line, indicating that they are performing far superior in each of these nonface tasks than predicted by their face scores. Female F2 (solid pink circle) fits into this category as well for all tests but one, cars. The scores of the other subjects (the three remaining women in pink) straddle the $45^{\circ}$ line with half the scores above and half below this line. These subjects therefore cannot be regarded as prosopagnosic only but also as 


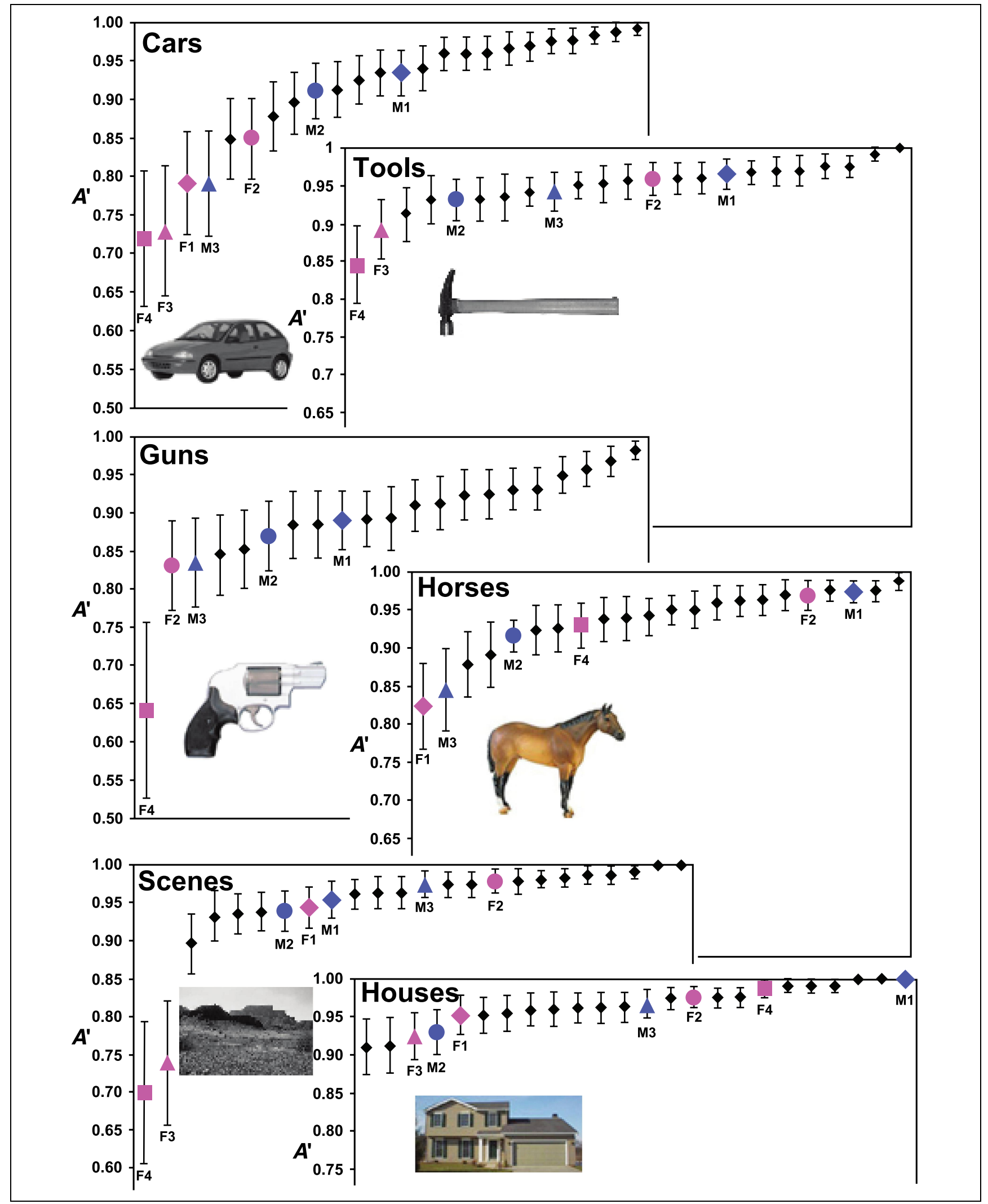

Figure 3. Individual distribution of simulated $A^{\prime}$ produced by bootstrapping analysis for nonface old/new discriminations. Scores have been sorted from low to high so that the rank of individual DPs is apparent. Error bars represent 1 standard deviation. 


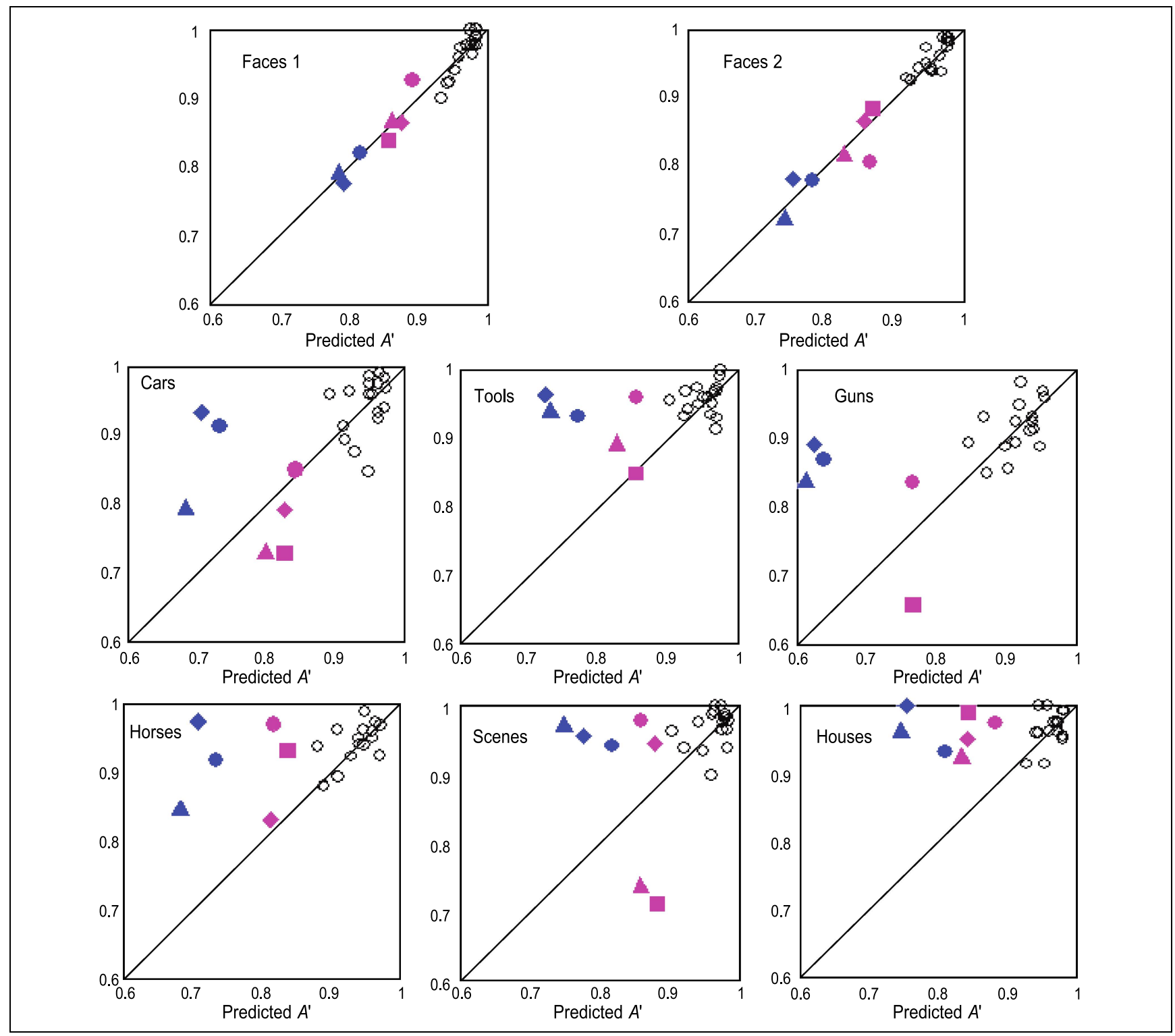

Figure 4. Plots displaying predicted $A^{\prime}$ scores and observed $A^{\prime}$ scores for control subjects (open circles) and DPs if the same mechanism was used to perform all of the discriminations. Predicted scores were generated by measuring subjects' ability with the face tests and then predicting their score by subtracting their ability from the difficulty of the test. If symbols are above the diagonal line, the observed score was greater than the predicted score; if below, the observed score was lower than predicted score.

agnosic. From these findings, we conclude that about half (4) the subjects are candidates for the designation of selective prosopagnosia, insofar they have deficits in face perception with normal abilities for other categories. Essentially, all of their object scores are well above that predicted from their abilities inferred from their face scores. Three of the subjects, on the other hand, cannot be regarded as purely prosopagnosic, because they have deficits with nonface classes.

\section{Can Face Selective Processing be Explained by Slow Reaction Times on Nonface Items?}

One of the main points of Gauthier et al. (1999) is that accuracy scores by themselves can be misleading. For example, it is possible that putative cases with facespecific prosopagnosia could spend a disproportionate amount of time with nonface tasks, perhaps adopting some kind of alternative strategy and thus elevating their score. Gauthier et al. point out that in the literature describing prosopagnosia there are few systematic reports of reaction times (RTs) for face and nonface tasks. Thus, longer opportunities to process nonface classes could explain their better abilities with these classes. This may be especially true for perceptual tasks in which piecemeal comparison of features is possible (Duchaine \& Weidenfeld, 2003).

We can test for this possibility by examining RTs for all subjects on all tests. If so-called prosopagnosic subjects were to adopt this strategy, then their RTs to nonface 
tests should be disproportionately long, especially in comparison to the RTs for faces. The table in the Appendix shows the RTs for all prosopagnosic and normal subjects. From this table, it is clear that a number of the DP's RTs are out of the normal range. What is important, however, is to determine whether the prosopagnosic subjects' RTs are disproportionately long for non-faces in comparison to faces. To evaluate this possibility, in Figure 5 we plot the relative slowness of RT of the prosopagnosic subjects on faces (the abscissa) versus the relative RTs responding to nonface classes (in $z$ score units derived from the normal controls). If prosopagnosic subjects are spending disproportionately more time with nonfaces than faces on tests each point on Figure 5 should be above the $45^{\circ}$ line of equivalence. This is clearly not the case. Ninety five percent of the RT scores are below this $45^{\circ}$ line, indicating that prosopag-

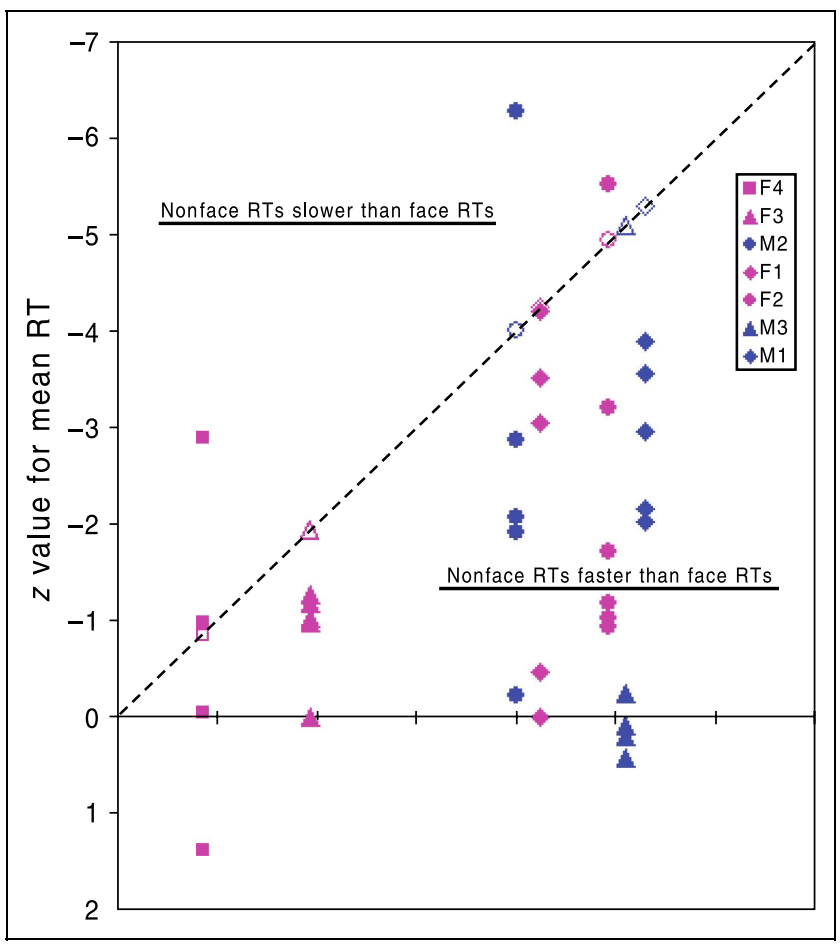

Figure 5. Comparison of $z$ score values for normalized response times for face and nonface tests for each prosopagnosic subject on the old/new discriminations. Large negative values indicate RTs much longer than the control mean RT. Note that the axes have been reversed. Each subject is represented by a particular color. The open symbol for each subject represents the average of that subject's $z$ scores for Faces 1 and Faces 2. The filled symbols represent $z$ scores for the response times for the nonface tests. Each DP's RT values are vertically aligned so that response times on the different tests can be compared (the $x$ value of every point is the face value for that DP). Nonface values that are above the diagonal are further from the control mean than the face value is, whereas values below the diagonal are closer to the control mean than the face value is (and oftentimes in the normal range). Speed-accuracy tradeoffs cannot account for a dissociation between impaired face discrimination and normal nonface discrimination if the nonface response time $z$ score is closer to the mean than the face response time $z$ score. nosia subjects do not spend a disproportionate amount of time looking at nonface objects as suggested by Gauthier et al. (1999), but do just the opposite. Prosopagnosic patients, as might be expected from their condition, are spending a disproportionate amount of time examining faces. Of the $22 A^{\prime}$ scores in the normal range, only two (F2-Houses; F4-Houses) had RT $z$ values that were lower than the average of the $z$ values from these subjects' RTs for the two face discriminations. As such, speed-accuracy tradeoffs cannot account for the dissociations seen with our prosopagnosic subjects. In fact, if speed-accuracy tradeoffs were operating, they lessened the number and magnitude of the dissociations in our $A^{\prime}$ results.

Note also that these dissociations cannot be explained by differential difficulty explanations (Gloning et al., 1970). Such explanations point out that if generalpurpose mechanisms were impaired, the impairment to the mechanisms would first be evident in particularly difficult discriminations. Because faces are a complex stimulus with high within-class similarity, it could be that face discriminations are simply more difficult than nonface discriminations. However, the average $A^{\prime}$ for the control subjects with faces was higher than their average $A^{\prime}$ scores with cars, guns, tools, and horses, and the average $A^{\prime}$ scores for faces were nearly identical to those for houses and scenes (see Figure 4). As a result, differential difficulty cannot account for the observed dissociations.

\section{DISCUSSION}

After demonstrating that seven DPs showed significant impairments in two separate old/new recognition memory tests with faces, we tested their nonface discrimination with six additional tests, each containing distinct categories of visual objects. If visual recognition is performed by a single mechanism (Tarr \& Cheng, 2003), the DPs should show impairments that are comparable to their impairments with faces. In contrast, if face recognition is performed by mechanisms different from those involved with other types of object recognition, then some of the DPs may show normal or relatively spared performance with the nonface categories.

We found clear dissociations between face and object recognition in four of the seven DPs. All were very impaired in multiple tests of face recognition but were not comparably impaired in the many tests with the other object classes. This indicates that these categories are, in fact, handled by different mechanisms. Our RT measures showed that long latencies cannot be responsible for these dissociations. In fact, our results went in the opposite direction predicted by such an account. Because we found dissociations in more than half of our seven subjects, it appears that dissociations of this type are not outliers but could be fairly typical in 
developmental prosopagnosia (see also Nunn et al., 2001; Bentin et al., 1999).

The results are consistent with results from a number of sources, which indicate that faces are processed differently than other classes of visual stimuli. Case studies have shown a number of individuals who show dissociations between face and nonface classes (Nunn et al., 2001; Henke et al., 1998; Farah, Levinson, et al. 1995; Farah, Wilson, et al., 1995), but the lack of RT measures has placed these reports in question. We found that RTs tend to be longest for prosopagnosics when confronted with face tasks so it seems likely that at least some of the earlier dissociations seen in acquired prosopagnosics were indeed dissociations between face and nonface recognition. Complementing these cases of prosopagnosia are case studies demonstrating that the converse dissociation, spared face recognition with severe object agnosia, can also exist (McMullen, Fisk, \& Phillips, 2000; Humphreys \& Rumiati, 1998; Moscovitch, Winocur, \& Behrmann, 1997). In addition to case studies, neuroimaging (Kanwisher, 2000; McCarthy, Puce, Gore, \& Allison, 1996), neurophysiology (Kreiman, Koch, \& Fried, 2000; Gross, Rocha-Miranda, \& Bender, 1972), and psychophysics (McKone et al., 2001; Tanaka \& Farah, 1993; Young et al., 1987) all provide evidence that faces and objects are processed by different mechanisms. Many hypotheses have attempted to characterize the domain of the recognition mechanisms used to process faces (Gauthier et al., 1999; Moscovitch et al., 1997; Farah, 1991; Levine \& Calvanio, 1989; Diamond \& Carey, 1986), but past cases of prosopagnosia and our current study do not provide a definitive answer.

The results also speak to the issue of classification of individuals with visual recognition impairments. Despite performing extremely poorly with faces in terms of accuracy and response time, many of our DPs were able to score in the normal range on nonface discriminations. Even more impressively, a few of the DPs (M1, M2, and F2) scored in the normal range on most or all of the nonface tasks. This demonstrates that prosopagnosia is not invariably accompanied by general agnosia. As a result, it appears that prosopagnosia is a condition that is distinct from agnosia. This conclusion is also powerfully reinforced by reports of agnosia without prosopagnosia (McMullen et al., 2000; Humphreys \& Rumiati, 1998; Moscovitch et al., 1997).

The dissociations seen in our sample are not only neuropsychological dissociations but also developmental dissociations. Individuals with these dissociations were unable to develop normal face processing, but they developed normal or near-normal abilities with some nonface classes. As a result, these results along with other developmental dissociations indicate that mechanisms used for face recognition and those used for nonface recognition are not constructed by the same developmental process (Duchaine, Nieminen-von Wendt, et al., 2003; Nunn et al., 2001; Bentin et al., 1999). These data do not yet allow us to make inferences about the nature of these dissociable developmental processes, but large numbers of selective cases of developmental agnosia should provide insight into these divisions (Duchaine, Nieminen-von Wendt, et al., 2003).

Unfortunately, the subject histories of these DPs and their experimental results do not hint at the developmental point at which the division between face and object recognition first emerges in the brain. Based on a case of putatively selective prosopagnosia due to brain damage the day after birth, Farah et al. (2000) argued that the division exists before any postnatal experience. This notion is consistent with evidence indicating that the development of configural processing involves a right hemisphere mechanism with an early critical period (Le Grand et al., 2001, 2003). However, the evidence for such an early distinction is sketchy, and future studies with DPs should shed light on this issue.

The picture emerging from studies of DP suggests that it is a quite heterogeneous condition. Not only do DPs vary quantitatively in their abilities with face recognition and their neural responses to faces (Hasson et al., 2003; Hadjikhani \& de Gelder, 2002), but they also show qualitatively different patterns of performance with other visual tasks. The DPs reported on here showed widely varying abilities with nonface categories, and as mentioned above, DPs have manifested normal and impaired abilities with many tasks other than recognition of facial identity (Galaburda \& Duchaine, 2003). Because a substantial and growing number of DPs are involved with research, this heterogeneity offers a promising means to characterize the mechanisms giving rise to face and object recognition.

\section{METHODS}

\section{Participants}

Eleven individuals who reported difficulties with face recognition made up our initial sample of DPs, and most of these individuals contacted our laboratory through our web site (www.faceblind.org). All complained of significant problems with face recognition in everyday life, and all recounted numerous experiences in which they were unable to recognize individuals after exposure that would be expected to lead to recognition in neurologically typical people. Many of these individuals also reported that they regularly recognized strangers as familiar. They ranged in age from 21 to 44, and all were in good health. Despite their impairments with visual recognition, some of these DPs have fairly normal professional and social lives, but their impairments are certainly troubling at times and sometimes cause great difficulties.

To determine whether these subjects were actually impaired with face recognition, they were tested with the Face One in Ten (OIT) and a test of famous face 
recognition. The OIT requires subjects to discriminate between a target individual and nontarget faces despite radically changing illumination. Three different target individuals are used, and the results from 400 trials are used to compute $d^{\prime}$, a measure of accuracy, and average $\mathrm{RT}$. The test is discussed in detail elsewhere (Duchaine, Nieminen-von Wendt, et al., 2003; Duchaine, 2000). In the famous face test, subjects were presented with images of celebrities from entertainment and politics cropped so that little hair or clothing was visible. Two different versions were used, one with 25 faces (Duchaine, Nieminen-von Wendt, et al., 2003; Duchaine, 2000) and one with 60 faces.

We dropped three individuals from our initial DP group, because their scores on the OIT, famous faces, and the two face old/new discriminations presented in the Results section did not conclusively demonstrate impairment with face recognition. We also dropped another individual, because he had difficulties with face categorization tasks ("Is this a face?"). This indicates that his face recognition impairments are due to mechanisms operating before recognition mechanisms, and so his results may not shed light on the operation of mechanisms used for the recognition of individual faces.

Five of the remaining seven individuals were out of the normal range on all four tests for either accuracy, response time, or both. The other two subjects (F3 and F4) were more than 2 standard deviations worse than the control participants on three of the four tests (see Figure 6), and the exception for both subjects was on the famous face test. However, both subjects were still more than 1.5 standard deviations below the mean with the famous faces. F3 has been discussed in a paper documenting her impaired facial identity recognition

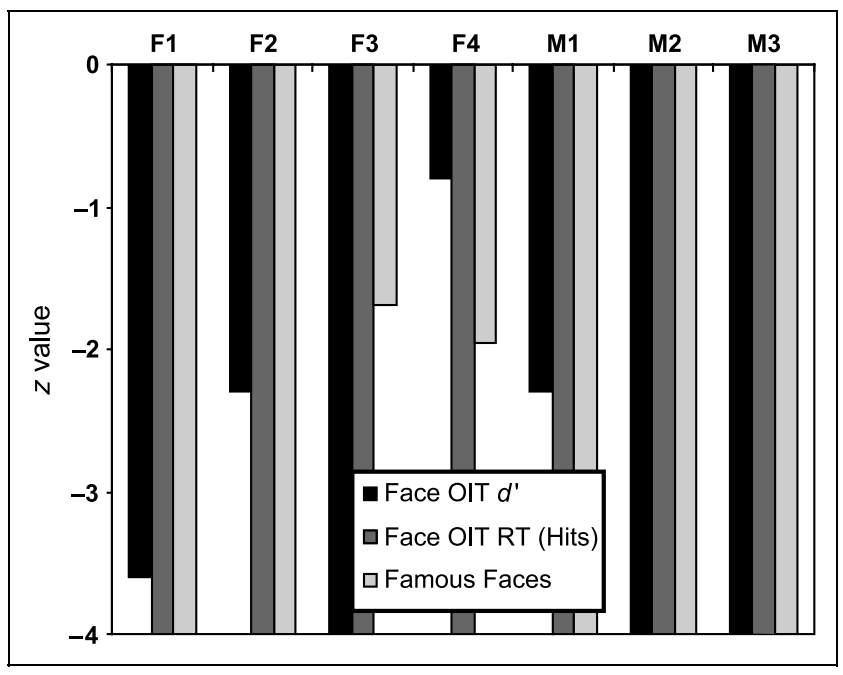

Figure 6. $z$ Scores for the DPs on the OIT and famous faces test, which contributed to our determination that a subject was actually a DP. In addition to these tests, we used performance on the two face old/new discrimination tests. The $A^{\prime}$ scores for the face old/new tests are displayed in Figure 2 and the RTs are displayed in Figure 5. coupled with her normal recognition of facial expressions of emotion. M3's face and nonface discrimination was reported on in another article (Duchaine, Nieminenvon Wendt, et al., 2003), and we included his results here to compare more DPs in a single study. Information about each subject is provided in Table 1 . All of these individuals performed normally on the perceptual tests in Birmingham Object Recognition Battery (Riddoch \& Humphreys, 1993) and had no difficulty recognizing common objects drawn from Snodgrass and Vanderwart's (1980) corpus of line drawings. Individuals listed as having likely genetic etiologies have parents or children with significant face recognition difficulties.

Seventeen graduate students (9 women and 8 men) served as control participants for the old/new recognition memory tests, and their mean age was 27.8 with a range from 24 to 34 . The control results showed no significant sex differences for any of the tests, and in fact, the means for each sex were extremely similar. Control subjects for the Face OIT were 13 undergraduate and graduate students. Control subjects for the famous faces tests were age-matched for the DPs, and each famous face control sample consisted of 15 or more subjects. All control participants and prosopagnosics participants had normal or corrected-to-normal vision.

\section{Stimuli}

In each old/new recognition memory test, 40 items from within a category were used. Ten items were target items, and they were shown during the study phase of the experiment. Thirty items were nontargets that were presented along with the target items during the test phase. See Figure 1 for examples.

\section{Faces 1 and Faces 2}

Grayscale yearbook photographs of women's faces were cropped so that very little or no hair was visible. To achieve a standard pose, some of the images were flipped or rotated. All of the images were the same size.

Table 1. Information on DP Subjects

\begin{tabular}{ccll}
\hline DP Subject & Age & Occupation & Probable Etiology \\
\hline F1 & 22 & Researcher & Unknown \\
F2 & 44 & Teacher & Unknown \\
F3 & 40 & Teacher & Genetic \\
F4 & 43 & Fitness instructor & Genetic \\
M1 & 21 & Teacher & Genetic \\
M2 & 22 & Student & Unknown \\
M3 & 41 & Engineer & Genetic \\
\hline
\end{tabular}

Individuals listed as having genetic etiologies have parents or children with significant face recognition difficulties. 


\section{Cars}

The cars used in these grayscale photographs had all conspicuous ornaments removed, and were placed on a white background facing the same direction. Each car was categorized into one of three styles (compact, sedan, or truck), and they were divided proportionally into targets and nontargets. The sizes of the cars were adjusted so that they were the proper size relative to the other cars.

\section{Tools}

Eight tool images were drawn from five categories (saws, hammers, pliers, wrenches, and screwdrivers), and these grayscale items were presented on a white background. Two items from each category were chosen as targets, and all items from particular categories were presented with a similar orientation and size.

\section{Guns}

Color images of handguns were used. All conspicuous decorations were erased, and the guns were presented in the same orientation and were scaled similarly.

\section{Horses}

The stimuli for this test consisted of color photographs of model horses made by Breyer Animal Creations placed on a white background. The photographs presented a side view of the horses, and their poses and sizes were similar.

\section{Natural Landscapes}

Grayscale photographs of natural landscapes that did not have any manmade structures were used. Eight landscapes were used from each of the following five categories: beaches, lakes, meadows, mountains, and deserts. Two images were chosen from each category to serve as targets. All images were the same size.

\section{Houses}

The color photographs used in this test contained typical looking houses photographed from the front with some of the yard surrounding the house visible. The sizes of the images were similar.

\section{Procedure}

Subjects were tested individually in a normally lit room, and were seated approximately $40 \mathrm{~cm}$ from the monitor.
Before each test, instructions were given both verbally and on the monitor to ensure that subjects understood the procedure. For the study portion, participants were presented with the 10 target items for 3 sec per item. The 10 items were cycled through twice so that control performance would be high enough to reveal impaired performance. The target images were identical throughout each task. During the test phase, participants were presented with items one at a time and were asked to respond whether an item was a target item (old) or a nontarget item (new) as quickly as possible with a mouse click. A total of 50 test items were presented consisting of 20 target items (10 targets $\times 2$ presentations) and 30 nontargets (30 nontargets $\times 1$ presentation). The order of the stimuli remained the same for all subjects so that test difficulty was the same for all subjects. Subjects were tested in the same order, and the testing was done on two different days. Day 1 included houses, cars, Faces 1, and horses; Day 2 included tools, Faces 2, natural landscapes, and guns.

\section{APPENDIX}

$z$ Values of Average RT for DPs on Each Old/New Discrimination

\begin{tabular}{lrrrrrrrrcc}
\hline \multicolumn{4}{c}{ Faces 1} & Faces 2 & \multicolumn{1}{c}{ Cars } & Houses & Scenes & Horses & Tools & Guns \\
\hline F1 & -5.62 & -2.87 & -0.46 & -4.19 & -3.05 & -3.50 & NA & NA \\
F2 & -7.03 & -3.04 & -3.21 & -5.51 & -1.18 & -1.72 & -0.93 & -1.01 \\
F3 & -2.63 & -1.24 & -1.27 & -1.02 & -1.18 & NA & -0.97 & NA \\
F4 & 0.33 & -2.04 & -0.03 & -2.89 & -0.99 & -0.04 & -0.97 & 1.38 \\
M1 & -4.37 & -5.93 & -2.01 & -3.55 & -2.95 & -3.89 & -2.96 & -2.16 \\
M2 & -3.20 & -4.80 & -0.22 & -2.06 & -6.26 & -2.86 & -2.86 & -1.90 \\
M3 & -1.92 & -8.21 & 0.09 & 0.43 & -0.24 & 0.20 & -0.23 & 0.21 \\
\hline
\end{tabular}

Negative $z$ values are produced by RTs that were longer than the control mean, whereas positive $z$ values are produced by RTs shorter than the control mean. These values are displayed in Figure 5.

\section{Acknowledgments}

This research was supported by the Nationals Institutes of Health (F32 MH64246-02 and RO1 EY13602). None of this work could have been done without the generous cooperation of the prosopagnosic subjects. We are very appreciative of their participation. The manuscript benefited greatly from the suggestions of Charles Nelson and two anonymous reviewers. Anne Grossetete provided invaluable statistical help and guidance. Some images were provided courtesy of Mike Tarr (Brown University, Providence, RI).

Reprint request should be sent to Brad Duchaine, Vision Sciences Laboratory, Harvard University, 7th Floor, 33 Kirkland Street, Cambridge, MA 02138, or via e-mail: brad@wjh. harvard.edu. 


\section{REFERENCES}

Barton, J. J., Cherkasova, M. V., Press, D. Z., Intrilligator, J. M., \& O'Connor, M. (2003). Developmental prosopagnosia: A study of three patients. Brain and Cognition, 51, 12-30.

Barton, J. J., Press, D. Z., Keenan, J. P., \& O'Connor, M., (2002). Lesions of the fusiform face area impair perception of facial configuration in prosopagnosia. Neurology, 58, 71-78.

Bentin, S., Deouell, L. Y., \& Soroker, N. (1999). Selective visual streaming in face recognition: Evidence from developmental prosopagnosia. NeuroReport, 10, 823-827.

Biederman, I. (1987). Recognition-by-components: A theory of human image understanding. Psychological Review, 94, 115-147.

Blair, R. J. R., Frith, U., Smith, N., Abell, F., \& Cipolotti, L. (2002). Fractionation of visual memory: Agency detection and its impairment in autism. Neuropsychologia, 40, $108-118$.

Blass, E. M., \& Camp, C. A. (2001). The ontogeny of face recognition: Eye contact and sweet taste induce face preference in 9- and 12-week-old human infants. Developmental Psychology, 37, 762-774.

Blass, E. M., \& Camp, C. A. (2004). The ontogeny of face identity; I. Eight- to 21-week-old infants use internal and external face features in identity. Cognition, 92, 305-327.

Bodamer, J. (1947). Die Prosopagnosie. Archiv Psychiatrische Nervenkrankheiten, 179, 6-54.

Bushnell, I. W. R., Sai, F., \& Mullin, J. T. (1982). Discrimination of faces by young infants. Journal of Experimental Child Psvchology, 33, 298-308.

Carey, S., \& Diamond, R. (1994). Are faces perceived as configurations more by adults than by children? Visual Cognition, 1, 253-274.

Carey, S., Diamond, R., \& Woods, B. (1980). The development of face recognition-A maturational component? Developmental Psvchology, 16, 257-269.

Cipolotti, L., Robinson, G., Blair, J., \& Frith, U. (1999). Fractionation of visual memory: Evidence from a case with multiple neurodevelopmental impairments. Neuropsuchologia, 37, 455-465.

Davies, S., Bishop, D., Manstead, A. S., \& Tantam, D. (1994) Face perception in children with autism and Asperger's syndrome. Journal of Child Psychologv and Psychiatry. 35, 1033-1057.

de Gelder, B., \& Rouw, R. (2000). Configural face processes in acquired and developmental prosopagnosia: Evidence for two separate face systems? NeuroReport, 11, 3145-3150.

de Haan, E. (1999). A familial factor in the development of face recognition deficits. Journal of Clinical and Experimental Neuropsychology, 21, 312-315.

De Renzi, E. (1986). Current issues in prosopagnosia. In H. D Ellis, M. A. Jeeves, F. Newcombe, \& A. W. Young (Eds.), Aspects of face processing (pp. 243-252). Dordrecht: Martinus Nijhoff.

Diamond, R., \& Carey, S. (1986). Why faces are and are not special: An effect of expertise. Journal of Experimental Psychology, 115, 107-117.

Duchaine, B. (2000). Developmental prosopagnosia with normal configural processing. NeuroReport, 11, 79-83.

Duchaine, B., Dingle, K., Butterworth, E., \& Nakayama, K. (2004). Normal greeble learning in a severe case of developmental prosopagnosia. Neuron, 43, 469-473.

Duchaine, B., Nieminen-von Wendt, T., New, J., \& Kulomaki, T. (2003). Dissociations of visual recognition in a developmental prosopagnosic: Evidence for separate developmental processes. Neurocase, 9, 380-389.

Duchaine, B., Parker, H., \& Nakayama, K. (2003). Normal emotion recognition in a prosopagnosic. Perception, 32 , 827-838.

Duchaine, B., \& Weidenfeld, A. (2003). An evaluation of two commonly used tests of unfamiliar face recognition. Neuropsychologia, 41, 713-720.

Efron, B., \& Tibshirani, R. J. (1993). An introduction to the bootstrap. Boca Raton, FL: Chapman \& Hall/CRC.

Farah, M. J. (1990). Visual agnosia: Disorders of object recognition and what they tell us about normal vision. Cambridge: MIT Press.

Farah, M. J. (1991). Patterns of co-occurrence among the associative agnosias: Implications for visual object representation. Cognitive Neuropsychology, 8, 1-19.

Farah, M. J., Levinson, K. L., \& Klein, K. L. (1995). Face perception and within-category discrimination in prosopagnosia. Neuropsychologia. 33, 661-674.

Farah, M. J., Rabinowitz, C., Quinn, G., \& Liu, G. T. (2000). Early commitment of neural substrates for face recognition. Cognitive Neuropsychology, 1-3, 117-123.

Farah, M. J., Wilson, K. D., Drain, H. M., \& Tanaka, J. R. (1995). The inverted face inversion effect in prosopagnosia: Evidence for mandatory, face-specific perceptual mechanisms. Vision Research, 35, 2089-2093.

Field, T. M., Woodson, R., Cohen, D., Greenberg, L., Garcia, R., \& Collins, K. (1982). Discrimination and imitation of facial expressions by neonates. Science, 218, 179-181.

Freire, A., Lee, K., \& Symons, L. A. (2000). The face-inversion effect as a deficit in encoding of configural information: Direct evidence. Perception, 29, 159-170.

Galaburda, A., \& Duchaine, B. (2003). Developmental disorders of vision. Neurologic Clinics, 21, 687-707.

Gauthier, I., Behrmann, M., \& Tarr, M. J. (1999). Can face recognition really be dissociated from object recognition? Journal of Cognitive Neuropsvchology 11, 349-370.

Goren, C., Sarty, M., \& Wu, P. (1975). Visual following and pattern discrimination of face-like stimuli by newborn infants. Pediatrics, 56, 544-549.

Grill-Spector, K. (2003). The neural basis of object perception. Current Opinion in Neurobiology, 13, 159-166.

Gross, C. G., Rocha-Miranda, C. E., \& Bender, D. B. (1972). Visual properties of neurons in inferotemporal cortex of the macaque. Journal of Neurophysiology, 35, 96-111.

Hadjikhani, N., \& de Gelder, B. (2002). Neural basis of prosopagnosia: An FMRI study. Human Brain Mapting 16, 176-182.

Hasson, U., Avidan, G., Deouell, L. Y., Bentin, S., \& Malach, R. (2003). Face-selective activation in a congenital prosopagnosic subject. Journal of Cognitive Neuroscience, 15, 419-431.

Haxby, J., Gobbini, M. I., Furey, M. L., Ishai, A., Schouten, J. L., \& Pietrini, P. (2001). Distributed and overlapping representations of faces and objects in ventral temporal cortex. Science, 293, 2425-2430.

Henke, K., Schwinbuerger, S. R., Grigo, A., Klos, T., \& Sommer, W. (1998). Specificity of face recognition: Recognition of exemplars of non-face objects in prosopagnosia. Cortex, 34, 289-296.

Humphreys, G., \& Rumiati, R. I. (1998). Agnosia without prosopagnosia or alexia: Evidence for stored visual memories specific to objects. Cognitive Neuropsychology $15,243-277$.

Itier, R. J., \& Taylor, M. J. (2004). Face inversion and contrast-reversal effects across development: In contrast to the expertise theory. Developmental Science, 7 , 246-260. 
Johnson, M. J., Dziurawiec, S., Ellis, H., \& Morton, J. (1991). Newborns' preferential tracking of face-like stimuli and its subsequent decline. Cognition, 40, 1-19.

Jones, R. D., \& Tranel, D. (2001). Severe developmental prosopagnosia in a child with superior intellect. Journal of Clinical and Experimental Neuropsychology, 23, 265-273.

Kanwisher, N. (2000). Domain specificity in face perception. Nature Neuroscience, 3, 759-763.

Kreiman, G., Koch, C., \& Fried, I. (2000). Category-specific visual responses of single neurons in the human medial temporal lobe. Nature Neuroscience, 3, 946-953.

Laeng, B., \& Caviness, V. S. (2001). Prosopagnosia as a deficit in encoding curved surface. Iournal of Cognitive Neuroscience, 13, 556-576.

Le Grand, R., Mondloch, C. J., Maurer, D., \& Brent, H. P. (2001). Early visual experience and face processing. Nature, 410, 890.

Le Grand, R., Mondloch, C. J., Maurer, D., \& Brent, H. P. (2003). Expert face processing requires visual input to the right hemisphere during infancy. Nature Neuroscience, 6 , 1108-1112.

Levine, D. N., \& Calvanio, R. (1989). Prosopagnosia: A defect in configural processing. Brain and Cognition, 10, 149-170.

Macmillan, N. A., \& Creelman, C. D. (1991). Detection theory: A user's guide. New York: Cambridge University Press.

McCarthy, G., Puce, A., Gore, J., \& Allison, T. (1996). Face-specific processing in the human fusiform gyrus. Iournal of Cognitive Neuroscience, 9, 605-610.

McConachie, H. R. (1976). Developmental prosopagnosia: A single case report. Cortex, 12, 76-82.

McKone, E., Martini, P., \& Nakayama, K. (2001). Categorical perception of face identity in noise isolates configural processing. Iournal of Experimental Psvchologv: Human Perception and Performance, 27, 573-599.

McMullen, P., Fisk, J. D., \& Phillips, S. (2000). Apperceptive agnosia and face recognition. Neurocase, 6, 403-414.

McNeil, J. E., \& Warrington, E. K. (1993). Prosopagnosia: A face-specific disorder. Quarterly Journal of Experimental Psychology, 46A, 1-10.

Michelon, P., \& Biederman, I. (2003). Less impairment in face imagery than face perception in early prosopagnosia. Neuropsvchologia, 41, 421-441.

Mondloch, C. J., Le Grand, R. L., \& Maurer, D. (2002).
Configural face processing develops more slowly than featural face processing. Perception, 31, 553-566.

Moscovitch, M., Winocur, G., \& Behrmann, M. (1997). What is special about face recognition? Nineteen experiments on a person with visual object agnosia and dyslexia but normal face recognition. Journal of Cognitive Neuroscience 9, 555-604.

Nunn, J. A., Postma P., \& Pearson, R. (2001). Developmental prosopagnosia: Should it be taken at face value? Neurocase 7, 15-27.

Pascalis, O., de Schonen, S., Morton, J., deRurelle, C., \& Fabre-Grenet, M. (1995). Mother's face recognition by neonates: A replication and an extension. Infant Behavior and Development, 8, 79-85.

Pietz, J., Ebeinger, F., \& Rating, D. (2003). Prosopagnosia in a preschool child with Asperger syndrome. Developmental Medicine and Child Neurology, 45, 55-57.

Riddoch, M. J., \& Humphreys, G. W. (1993). BORB: Birmingham Object Recognition Battery. Hove: Erlbaum.

Sackett, G. P. (1966). Monkeys reared in isolation with pictures as visual input: Evidence for an innate releasing mechanism. Science, 154, 1468-1473.

Slater, A., Bremner, J. G., Slater, A. M., \& Mason, U. C. (2000). The role of facial orientation in newborn infants' preference for attractive faces. Developmental Science, 3, 181-185.

Slater, A., Von der Schulenburg, C., Brown, E., Badenoch, M., Butterworth, G., Parsons, S., \& Samuels, C. (1998).

Newborn infants prefer attractive faces. Infant Behavior and Development, 21, 345-354.

Snodgrass, J. G., \& Vanderwart, M. (1980). Journal of Experimental Psychology: Human Learning Memory, 6, $174-215$.

Tanaka, J. W., \& Farah, M. J. (1993). Parts and wholes in face recognition. Quarterly Journal of Experimental Psychology, 46A, 225-245.

Tarr, M. J., \& Cheng, Y. D. (2003). Learning to see faces and objects. Trends in Cognitive Science, 7, 23-30.

Tranel, D., \& Damasio, A. (1989). Developmental prosopagnosia? A new form of learning and recognition defect. Society for Neuroscience Abstracts, 15, 303.

Young, A. W., Hellawell, D., \& Hay, D. (1987). Configurational information in face perception. Perception, 16, 747-759.

Yovel, G., \& Kanwisher, N. (in press). Face perception: Domain-specific, not process-specific. Neuron. 


\section{This article has been cited by:}

1. L. Garrido, N. Furl, B. Draganski, N. Weiskopf, J. Stevens, G. C.-Y. Tan, J. Driver, R. J. Dolan, B. Duchaine. 2010. Voxel-based morphometry reveals reduced grey matter volume in the temporal cortex of developmental prosopagnosics. Brain 132:12, 3443-3455. [CrossRef]

2. J. J. S. Barton, H. Hanif, S. Ashraf. 2010. Relating visual to verbal semantic knowledge: the evaluation of object recognition in prosopagnosia. Brain 132:12, 3456-3466. [CrossRef]

3. Grit Herzmann, Olga Kunina, Werner Sommer, Oliver Wilhelm. Individual Differences in Face Cognition: Brain-Behavior RelationshipsIndividual Differences in Face Cognition: Brain-Behavior Relationships. Journal of Cognitive Neuroscience, ahead of print571-589. [Abstract] [PDF] [PDF Plus]

4. Carlo Giussani, Franck-Emmanuel Roux, Lorenzo Bello, Valérie Lauwers-Cances, Costanza Papagno, Sergio M. Gaini, Michelle Puel, Jean-François Démonet. 2009. Who is who: areas of the brain associated with recognizing and naming famous faces. Journal of Neurosurgery 110:2, 289-299. [CrossRef]

5. Bradley Duchaine. 2008. Comment on prevalence of hereditary prosopagnosia (HPA) in Hong Kong Chinese population. American Journal of Medical Genetics Part A 146A:22, 2860-2862. [CrossRef]

6. Ingo Kennerknecht, Nga Yee Ho, Virginia C.N. Wong. 2008. Prevalence of hereditary prosopagnosia (HPA) in Hong Kong Chinese population. American Journal of Medical Genetics Part A 146A:22, 2863-2870. [CrossRef]

7. R. Righart, B. de Gelder. 2007. Impaired face and body perception in developmental prosopagnosia. Proceedings of the National Academy of Sciences 104:43, 17234-17238. [CrossRef]

8. Shlomo Bentin, Joseph M. DeGutis, Mark D'Esposito, Lynn C. Robertson. 2007. Too Many Trees to See the Forest: Performance, Event-related Potential, and Functional Magnetic Resonance Imaging Manifestations of Integrative Congenital ProsopagnosiaToo Many Trees to See the Forest: Performance, Event-related Potential, and Functional Magnetic Resonance Imaging Manifestations of Integrative Congenital Prosopagnosia. Journal of Cognitive Neuroscience 19:1, 132-146. [Abstract] [PDF] [PDF Plus]

9. Leslie A. Zebrowitz. 2006. Finally, Faces Find Favor. Social Cognition 24:5, 657-701. [CrossRef]

10. Galit Yovel, Brad Duchaine. 2006. Specialized Face Perception Mechanisms Extract Both Part and Spacing Information: Evidence from Developmental ProsopagnosiaSpecialized Face Perception Mechanisms Extract Both Part and Spacing Information: Evidence from Developmental Prosopagnosia. Journal of Cognitive Neuroscience 18:4, 580-593. [Abstract] [PDF] [PDF Plus]

11. Justin Storbeck, Michael D. Robinson, Mark E. McCourt. 2006. Semantic Processing Precedes Affect Retrieval: The Neurological Case for Cognitive Primacy in Visual Processing. Review of General Psychology 10:1, 41-55. [CrossRef]

12. Galia Avidan , Uri Hasson , Rafael Malach , Marlene Behrmann . 2005. Detailed Exploration of Face-related Processing in Congenital Prosopagnosia: 2. Functional Neuroimaging FindingsDetailed Exploration of Face-related Processing in Congenital Prosopagnosia: 2. Functional Neuroimaging Findings. Journal of Cognitive Neuroscience 17:7, 1150-1167. [Abstract] [PDF] [PDF Plus]

13. Marlene Behrmann, Galia Avidan, Jonathan J. Marotta, Rutie Kimchi . 2005. Detailed Exploration of Face-related Processing in Congenital Prosopagnosia: 1. Behavioral FindingsDetailed Exploration of Face-related Processing in Congenital Prosopagnosia: 1. Behavioral Findings. Journal of Cognitive Neuroscience 17:7, 1130-1149. [Abstract] [PDF] [PDF Plus]

14. Frank KeilCognitive Science and Cognitive Development . [CrossRef] 